\title{
A STUDY ON THE CORROSION PROCESES OF EUTECTIC SOLDER Bi-42Sn ALLOY
}

\author{
Nguyen Dang Nam \\ Petroleum Department, Petrovietnam University, \\ Ba Ria City, Ba Ria - Vung Tau Province, 74000, Vietnam \\ Email: namnd@pvu.edu.vn
}

Received: 14 March 2014, Accepted for publication: 11 October 2014

\begin{abstract}
The change of impedance of the passive, repassive states together with initial pitting process of eutectic Sn-Bi alloy is studied. Anodic polarization measurements were performed to evaluate the passive, pitting, and repassive states and the actual results used to assure the accuracy of the impedance results. X-ray photoelectron spectroscopy indicates that Sn oxides interact with $\mathrm{Bi}$ oxides to form a passive film. The dissolution of Bi results in the initial pitting and $\mathrm{Sn}$ oxides form the repassive film.
\end{abstract}

Keywords: Sn-Bi alloy, corrosion, electrochemical reactions, electrochemical impedance spectroscopy.

\section{INTRODUCTION}

Potentiodynamic polarization is a surpassed technique for investigation of passive, pitting and repassive phenomenon. However, it is not possible to obtain impedance information with these polarizations. Electrochemical impedance spectroscopy (EIS) is a recommended method to study passive layer breakdown phenomenon [1 - 3]. Unfortunately, the initiation and development states of pits are not stable processes. Therefore, methods such as dynamic electrochemical impedance spectroscopy (DEIS) have been used to study the aforementioned states in the stable range of potential $[4$ - 6]. This method detects and analyzes an electrochemical response at the interface which functions as both frequency and electrode potential. The DEIS results acquire both impedance and current densities as functions of the potential in a potential scan, suggesting that it is possible to evaluate the interrelated processes in case of non stationary interface between film and metal [7, 8]. Thus, the interest and importance of the passive, pitting and repassive phenomenon suggests the development and practical application of the methods as the need of the hour in order to analyze the defined states. In the case of passive, pitting, and repassive states, the full impedance spectra could be procured and evaluated.

Eutectic alloys are the basis of engineering materials due to the relationship between the microstructure and the solidification conditions in both scientific and technological reasons [9 15]. $\mathrm{Sn}-\mathrm{Pb}$ alloy is a common materials used in industrial solder materials. However, Lead is 
dangerous to the environment and human health as it is a highly toxic element [16]. Therefore, design and development of lead-free solder appears to be of prime importance in material science with the intention of being affable with environment. Eutectic Bi-42Sn solder is a potential alternative for $\mathrm{Sn}-37 \mathrm{~Pb}$ solder that is applied in consumer products [17 - 21]. The current assembly material set could be retained as the melting temperature of $\mathrm{Bi}-42 \mathrm{Sn}$ solder is $139{ }^{\circ} \mathrm{C}$ [22]. In this paper we present the results of impedance investigations under potential applied to eutectic $\mathrm{Bi}-42 \mathrm{Sn}$ alloy which has not been investigated till date as of our knowledge. This method of impedance measurement realization is not only pronounced but also novel and determine a potential for passive, pitting, and repassive corrosion investigation.

\section{EXPERIMENTAL}

The eutectic sample (Bi-42 wt.\% Sn) was prepared by melting the weighed quantities of highly pure $\mathrm{Sn}$ and $\mathrm{Bi}(>99.99 \%)$ metals in a graphite crucible in a vacuum melting furnace. The corresponding elemental distributions were observed by electron probe microanalysis (EPMA) after polishing with $0.1 \mu \mathrm{m}$ alumina powder. All of the electrochemical experiments were performed at room temperature by immersing samples in $0.10 \mathrm{M} \mathrm{Na}_{2} \mathrm{CO}_{3}$ with $0.00,0.26$, and $0.60 \mathrm{M} \mathrm{NaCl}$ additives in solution. In this solution, the $\mathrm{Cl}^{-}$ion additives induce pit initiation but the $\mathrm{CO}_{3}{ }^{2-}$ ion additives retard the incorporation of $\mathrm{Cl}^{-}$ions into the oxide film on the alloy surface so that they practically impede pit initiation. The specimens for electrochemical tests were prepared by grinding with 600-grit silicon carbide paper. The exposed area was $1.77 \mathrm{~cm}^{2}$. A graphite counter electrode was used, with a saturated calomel electrode (SCE) as the reference. Anodic polarization was performed using an EG\&G PAR 273A potentiostat for DC measurements. Prior to the anodic polarization test, the samples were immersed in the solution for $3 \mathrm{~h}$ in order to stabilize the open-circuit potential (OCP). The potential of the electrodes was swept at a rate $0.166 \mathrm{mV} / \mathrm{s}$ in the range from the initial potential of corrosion potential $\left(\mathrm{E}_{\text {corr }}\right)$ to $1600 \mathrm{mV}_{\text {SCE}}$. The dynamic electrochemical impedance spectroscopy measurements were conducted using a VMP2 system with a commercial software program for the AC measurements. The potential step was $10 \mathrm{mV}_{\mathrm{SCE}}$ and amplitude of the sinusoidal perturbation was $10 \mathrm{mV}$. The frequency range was from $100 \mathrm{kHz}$ to $10 \mathrm{mHz}$. Tests were conducted in the range from initial potential of $-400 \mathrm{mV}_{\text {SCE }}$ to the final potential of $1600 \mathrm{mV}_{\text {SCE }}$. The surface films in the OCP, passive, and repassive states were examined by X-ray photoelectron spectroscopy (XPS) after 3 $\mathrm{h}$ OCP, and stable passive and enriched repassive films.

\section{RESULTS AND DISCUSION}

EPMA analysis was performed to determine the elemental distribution of $\mathrm{Bi}$ and $\mathrm{Sn}$ in the microstructure as shown in Fig. 1. Bi and Sn elements are found to be alternately enriched in the microstructure. Overall, the microstructure included two primary $\alpha$ grain surrounded by a eutectic mixture of Bi and Sn. 


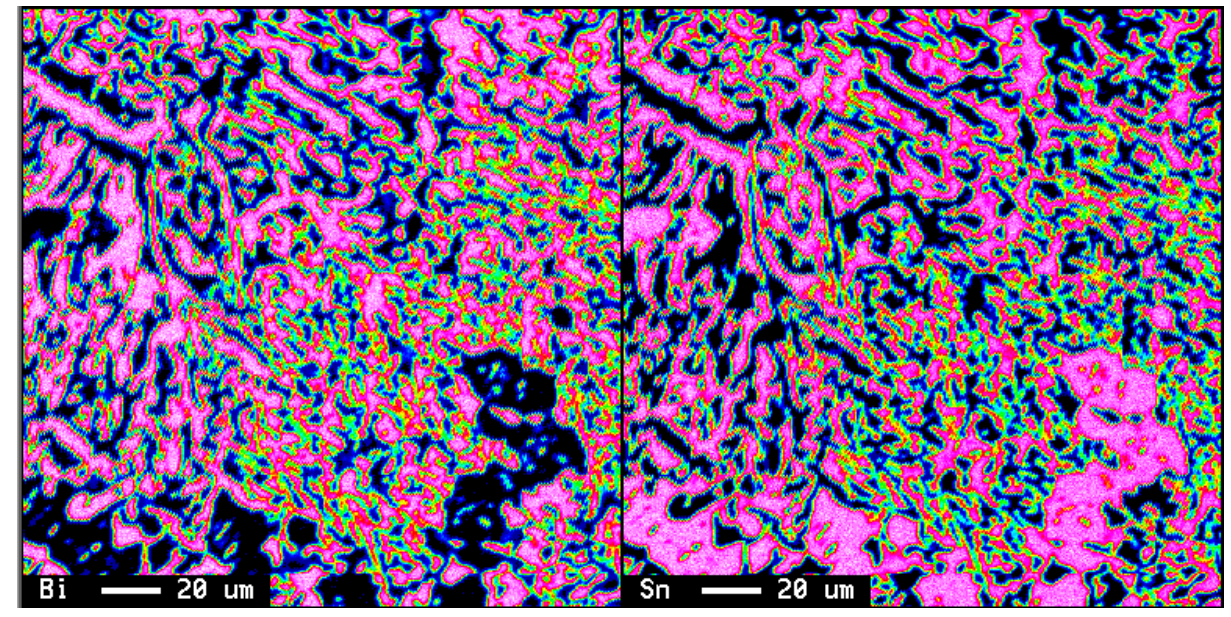

Figure 1. EPMA mapping of alloying elements on the surface of the Bi-42Sn alloy.

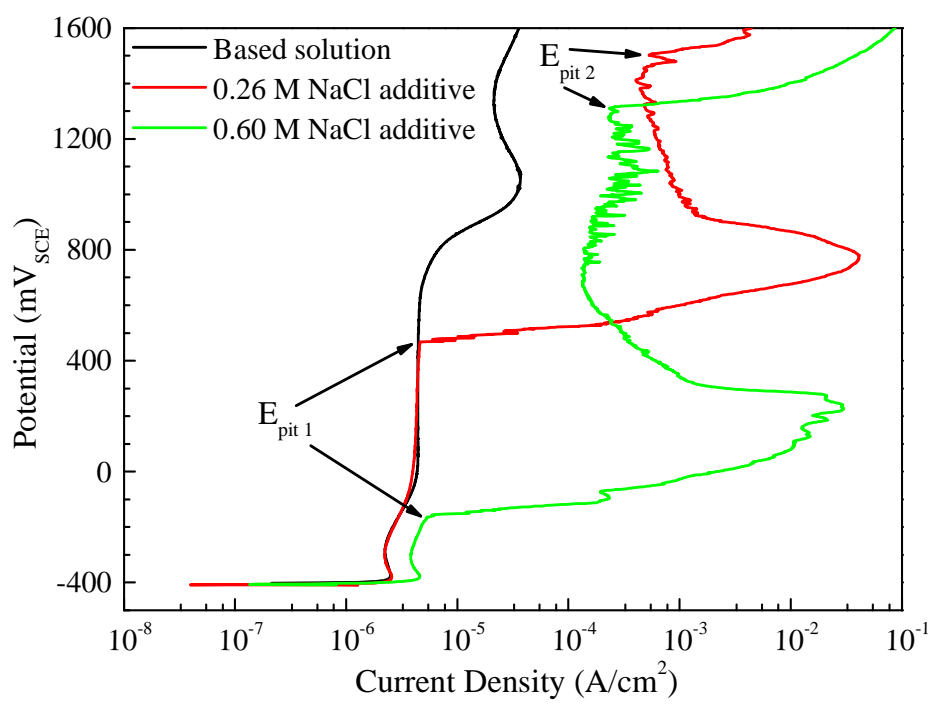

Figure 2. Anodic polarization curves of Bi-42Sn alloy as a function of chloride concentrations in $0.1 \mathrm{M} \mathrm{Na}_{2} \mathrm{CO}_{3}$ solution.

The anodic polarization curves for the Bi-42 wt \% Sn are shown in Fig. 2. The 0.00 and $0.26 \mathrm{M} \mathrm{NaCl}$ additive condition were well passivated with a low passive current density and the range of the passive potential increased with decreasing chloride concentration in solution. A decrease in the passive potential range and an increase in passive current density were observed with increase of chloride concentration in solution due to the breakdown of passive films.

Figure 3 shows the Nyquist plots obtained from DEIS of Bi-42Sn alloy in $\mathrm{Na}_{2} \mathrm{CO}_{3}$ with $0.00,0.26$, and $0.60 \mathrm{M} \mathrm{NaCl}$ additives. The impedance of the alloy specimen in solution without chloride additive showed much larger impedance than that in solution containing chloride and decreased with increase of chloride concentration. A successive change in the shape of each impedance state with potential is shown in the diagram. For the initial potentials, the impedance spectra shows the formation of semicircles which increases with increasing potentials, indicating an enriched passive film. Initially pitting was observed due to the sudden drop of impedance at 
467 and $-100 \mathrm{mV}_{\mathrm{SCE}}$ for alloy in solution containing 0.26 and $0.60 \mathrm{M} \mathrm{NaCl}$. At higher potential, impedance started to increase and retained the formation of semicircles due to repassivation, while at the final potentials the impedance decreased again and take the form of capacitance, suggesting that the repassive film was fully broken down. Lower impedance, earlier pitting initiation and fully broken down of passive film was observed at higher chloride concentrations. DEIS results indicated that the electrochemical processes correspond to the results of the anodic polarizations.

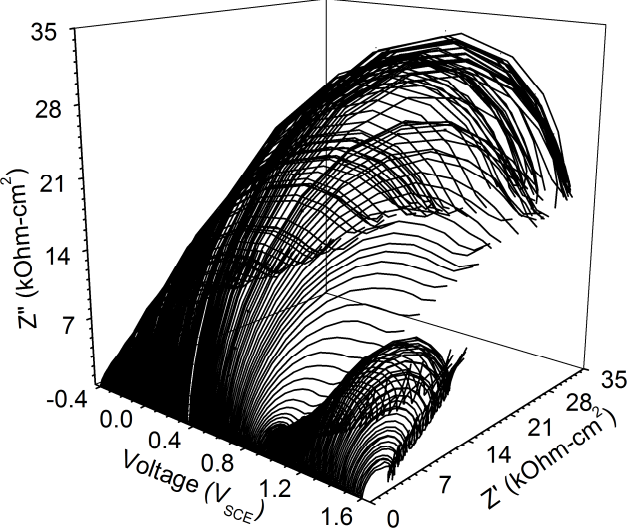

(a)

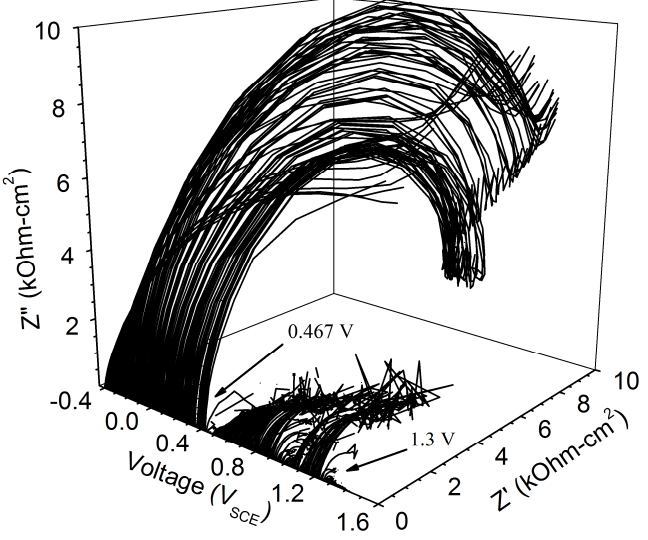

(b)

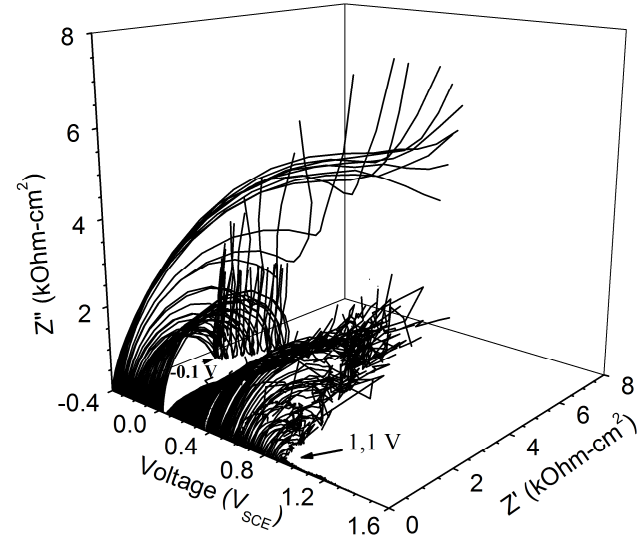

(c)

Figure 3. Variation of the impedance spectra of Bi-42Sn alloy as a function of potentials in $0.10 \mathrm{M}$ $\mathrm{Na}_{2} \mathrm{CO}_{3}$ with (a) 0.00 , (b) 0.26 , and (c) $0.60 \mathrm{M} \mathrm{NaCl}$ additives.

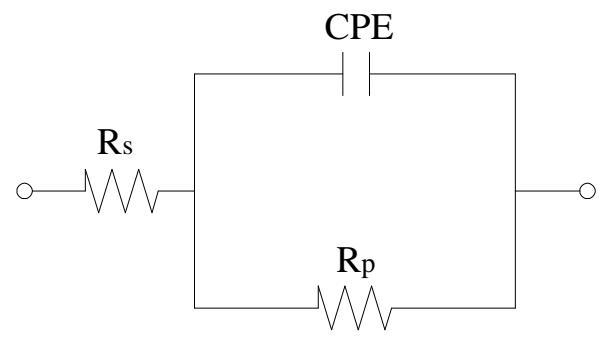

(a)

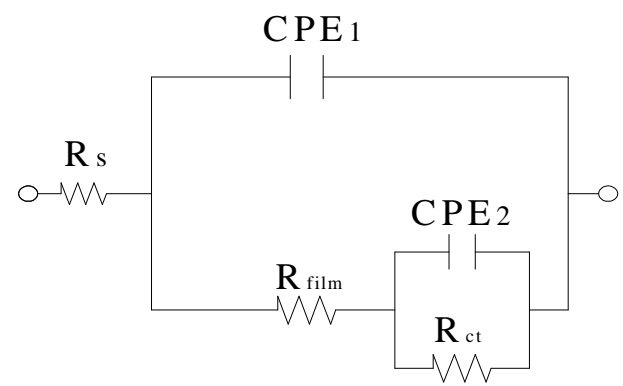

(b)

Figure 4. Equivalent circuit model for fitting of: (a) the breakdown film and (b) the film formation on Bi-42Sn alloy surfaces. 
The electrochemical response to the impedance tests for the materials under consideration was best simulated with the equivalent circuits which are checked by ZWimpWin program.

The results shows that $\mathrm{R}_{\mathrm{s}}\left(\mathrm{CPE}_{\mathrm{dl}} \mathrm{R}_{\mathrm{ct}}\right)$ in Fig. 4 (a) is an equivalent circuits that used for fitting the breakdown film, while $R_{s}\left(C E_{\text {film }}\left(R_{\text {film }}\left(C E_{\text {dl }} R_{c t}\right)\right)\right.$ ) in Fig. 4 (b) is suitable for fitting the passive and repassive film, where $\mathrm{R}_{\mathrm{s}}$ represents the solution resistance, $\mathrm{CPE}$ - the constant phase element, $R_{p}$ - the polarization resistance, $R_{\text {film }}$ - the film resistance, and $R_{c t}$ - the charge transfer resistance. The high- $\left(\mathrm{R}_{\text {film }}\right)$ and low- $\left(\mathrm{R}_{\mathrm{ct}}\right)$ frequency resistance components were affected by the $\mathrm{Cl}^{-}$additive. In this case, the capacitor was replaced with a CPE to improve the fitting quality, where the CPE contained a double-layer capacitance $(\mathrm{C})$ and phenomenological coefficient $(\mathrm{n})$. The $\mathrm{n}$ value of a CPE indicates its meaning: $\mathrm{n}=1$, a capacitance; $\mathrm{n}=0.5$, a Warburg impedance; $n=0$, a resistance and $n=-1$, an inductance. In the present study, $n$ was consistently maintained near 0.8 , as a result of the deviation from ideal dielectric behavior.

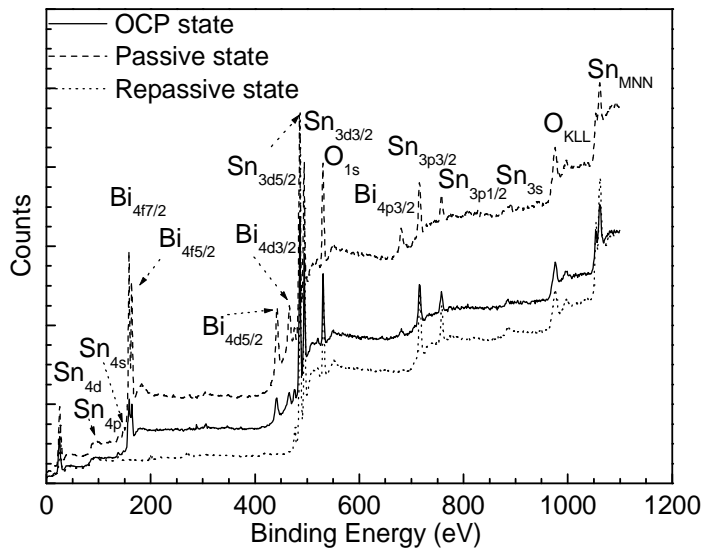

(a)
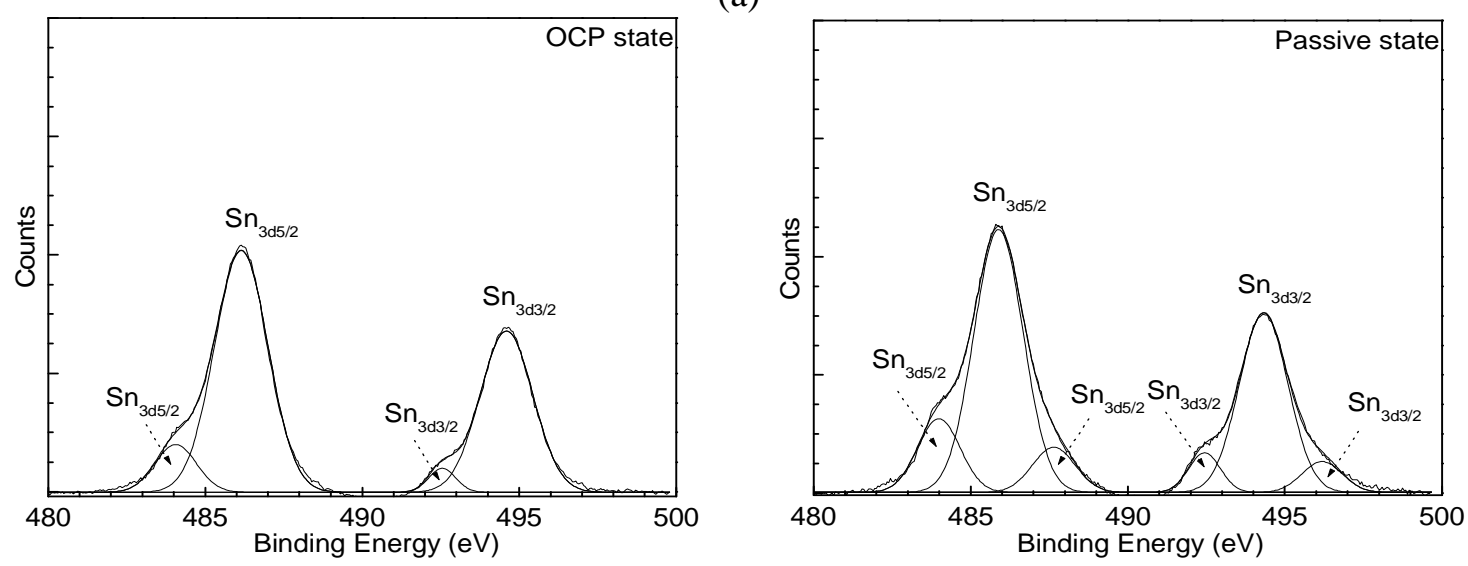

Figure 5. XPS peak analysis for the surface films at different states of the Bi-42Sn alloy (a) survey scan spectra. 


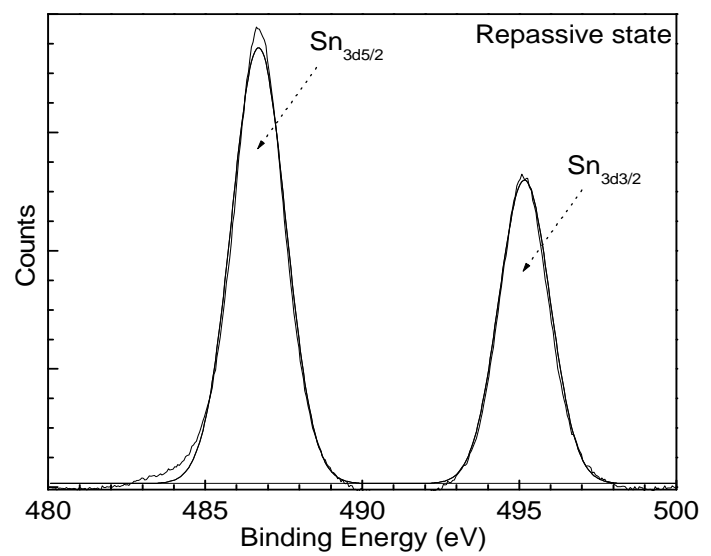

(b)
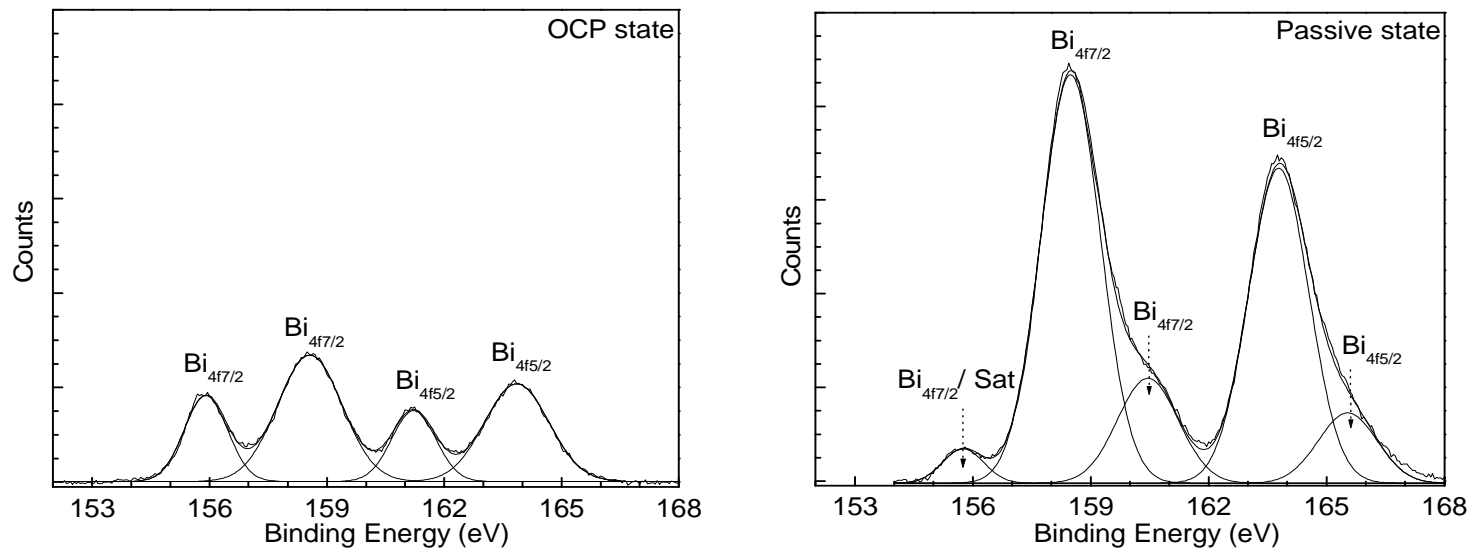

(c)
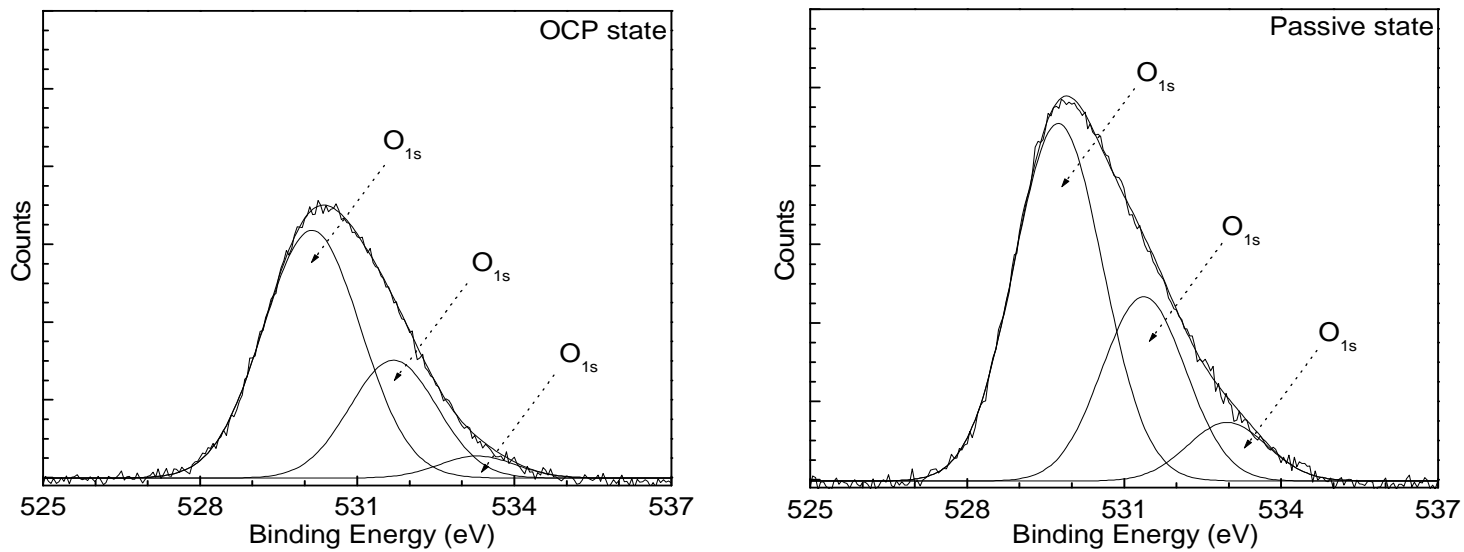

Figure 5. XPS peak analysis for the surface films at different states of the Bi-42Sn alloy: survey scan narrow scan spectra of (b) Sn, (c) Bi 


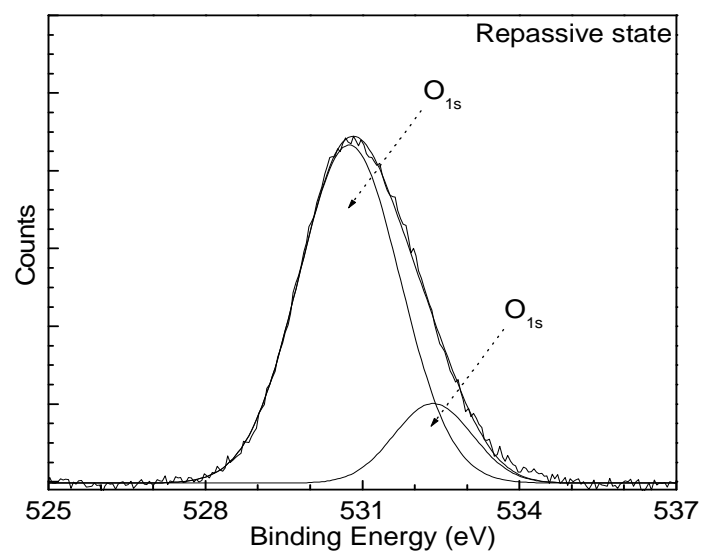

(d)

Figure 5. XPS peak analysis for the surface films at different states of the Bi-42Sn alloy: survey scan spectra and narrow scan spectra (d) O.

The surface films in the OCP, passive, and repassive states were examined by X-ray photoelectron spectroscopy after $3 \mathrm{~h} \mathrm{OCP}$, stable passivation and enriched repassivation as shown in Fig. 5. It indicates that the peaks of $\mathrm{Bi}, \mathrm{Sn}$, and $\mathrm{O}$ exist. The binding energy of $\mathrm{Sn}$ $3 \mathrm{~d} 3 / 2$ and $\mathrm{Sn} 3 \mathrm{~d} 5 / 2$ was around 494 and $485 \mathrm{eV}$, respectively. The presence of $\mathrm{Sn}$ oxides/hydroxides on the surfaces indicates that the Sn oxides/hydroxides are present in OCP, passive and repassive states. Moreover, these Sn oxides could be observed at repassive state as the highest peak. No Bi products were obtained in the repassive state, suggesting that Bi had no contribution in this state, while Bi oxides/hydroxides were detected in OCP and passive states as shown in Fig. 5 (c). In addition, Fig. 5 (d) indicates that the $\mathrm{O}$ 1s spectra were composed of three peaks corresponding to the signals from oxygen in form of the oxide around $530 \mathrm{eV}$ and oxygen in the hydroxyl groups around $531 \mathrm{eV}$ and $533 \mathrm{eV}$. The XPS result indicated that passive film was formed as a result of an interaction of $\mathrm{Sn}$ oxides with $\mathrm{Bi}$ oxides which plays a most significant role in improving the surface film of $\mathrm{Bi}-42 \mathrm{Sn}$ alloy, whereas $\mathrm{Sn}$ oxides result in repassivation.

A model for the mechanism (in Fig. 6) of the corrosive damage of the alloy can be described with the following three processes: (1) The first step is the formation of the passive film in a specified solution due to the formation of passive film by Sn and Bi oxides interaction. (2) At the weak points on the passive surface, where Bi would be diffused which causes the initial breakdown of passive film as it exceeds the critical stability of the passive film in chloride environment. (3) As soon as passive film was broken down, repassivation would be initiated due to the formation of stable $\mathrm{Sn}$ oxides which promotes repassivation of alloy surface. 


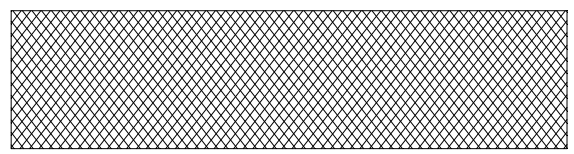

Bi-42Sn alloy

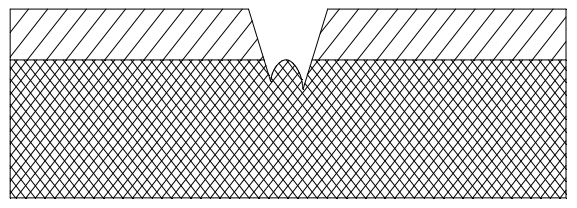

Initial pitting

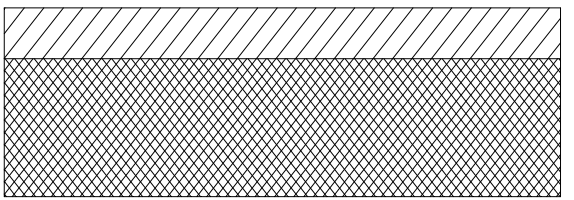

Passive state

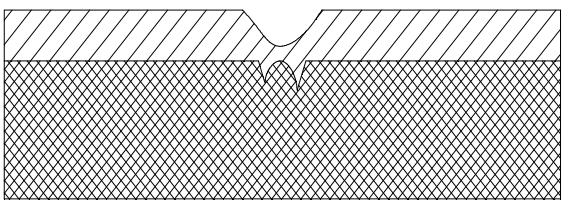

Repassive state

Figure 6. Schematic figure of corrosive processes of $\mathrm{Bi}-42 \mathrm{Sn}$ alloy in $0.1 \mathrm{M} \mathrm{Na}_{2} \mathrm{CO}_{3}$ solution containing chloride.

\section{CONCLUSIONS}

This paper reports the advantage of the DEIS for examining the surfaces in terms of the passivation state, initial pitting process as well as the repassivation state. Excellent agreement was observed between the DEIS and the anodic polarization. In addition, the films components of the indicated alloy were also identified in the OCP, passive, and repassive states. The results suggest that the $\mathrm{Sn}$ and $\mathrm{Bi}$ oxides interact to form passive film, while $\mathrm{Sn}$ oxides cause the formation of the repassive film. In addition, it was confirmed that dissolution of Bi could cause the initial pitting.

Acknowledgement. The author is grateful for the support of Vietnam Oil and Gas Group, PetroVietnam University.

\section{REFERENCES}

1. Nam N. D., Kim W. C., Kim J. K., Shin K. S., Jung H. C. - Corrosion resistance of Mg5Al-xSr alloys, J. Alloys Compd. 59 (2011) 4839-4847.

2. Nam N. D., Bian M. Z., Forsyth M., Seter M., Tan M., Shin K. S. - Effect of calcium oxide on the corrosion behaviour of AZ91 magnesium alloy, Corros. Sci. 64 (2012) 263-271.

3. Nam N. D., Kim W. C., Kim J. K., Shin K. S., Jung H. C. - Effect of mischmetal on the corrosion properties of Mg-5Al alloy, Corros. Sci. 51 (2009) 2942-2949.

4. Ragoisha G. A., Bondarenko A. S. - Potentiodynamic electrochemical impedance spectroscopy, Electrochim. Acta 50 (2005) 1553-1563.

5. Ragoisha G. A., Bondarenko A. S. - Potentiodynamic electrochemical impedance spectroscopy for solid state chemistry, Solid State Phenom. 90-91 (2003) 103-108.

6. Ragoisha G. A., Bondarenko A. S. - Potentiodynamic electrochemical impedance spectroscopy. Copper underpotential deposition on gold, Electrochem. Commun. 5 (2003) 392-395. 
7. Darowicki K., Slepski P. - Dynamic electrochemical impedance spectroscopy of the first order electrode reaction, J. Electroanal. Chem. 547 (2003) 1-8.

8. Darowicki K., Orlikowski J., Lentka G. - Instantaneous impedance spectra of a nonstationary model electrical system, J. Electroanal. Chem. 486 (2000) 106-110.

9. McLean M, Directionally Solidified Materials for High Temperature Service, The Metal Society Book, London (1983).

10. Stefanescu D. M., Abbaschian G. J., Bayuzick R. J., Solidification Processing of Eutectic Alloy, American Society for Metals, OH (1988).

11. Hu X., Chan Y. C., Zhang K., Yung K. C. - Effect of graphene doping on microstructural and mechanical properties of $\mathrm{Sn}-8 \mathrm{Zn}-3 \mathrm{Bi}$ solder joints together with electromigration analysis, J. Alloys Compd. 580 (2013) 162-171.

12. $\mathrm{Hu} \mathrm{X}$., Li K., Min Z. - Microstructure evolution and mechanical properties of $\mathrm{Sn} 0.7 \mathrm{Cu} 0.7 \mathrm{Bi}$ lead-free solders produced by directional solidification, J. Alloys Compd. 566 (2013) 239-245.

13. Magnin P., Mason J. T., Trivedi R. - Growth of irregular eutectics and the Al-Si system, Acta metall. 39 (1991) 469-480.

14. Bui Q. V., Jung S. B. - Characterization of low speed shear test reliability of Sn-1.0AgXCe/ENEPIG solder joint, J. Alloys Compd. 560 (2013) 54-61.

15. Bui Q. V., Nam N. D., Noh B. I., Kar A., Kim J. G., Jung S. B. - Effect of Ag addition on the corrosion properties of Sn-based solder alloys, Matter Corros. 61 (2010) 30-33.

16. Abrahams P. W., Follansbee M. H., Hunt A., Smith B., Wragg J. - Iron nutrition and possible lead toxicity: An appraisal of geophagy undertaken by pregnant women of UK Asian communities, Appl. Geochem. 21 (2006) 98-108.

17. Xu G., Guo F., Wang X., Xia Z., Lei Y., Shi Y., Li X. - Retarding the electromigration effects to the eutectic $\mathrm{SnBi}$ solder joints by micro-sized Ni-particles reinforcement approach, J. Alloys Compd. 509 (2011) 878-884.

18. Shiue Y.Y., Chuang T.H. - Effect of La addition on the interfacial intermetallics and bonding strengths of $\mathrm{Sn}-58 \mathrm{Bi}$ solder joints with $\mathrm{Au} / \mathrm{Ni} / \mathrm{Cu}$ pads, J. Alloys Compd. 491 (2010) 610-617.

19. Liang K., Tang X., Yu L., Wang N., Hu W. - Investigation of preparation and characteristics of Sn-Bi eutectic powders derived from a high shear mechanical approach, J. Alloys Compd. 509 (2011) 9836-9841.

20. Shen L., Lu P., Wang S., Chen Z. - Creep behaviour of eutectic Sn-Bi alloy and its constituent phases using nanoindentation technique, J. Alloys Compd. 574 (2013) 98-103.

21. Osório W. R., Peixoto L. C., Garcia L.R., Oël N.M., Garcia A. - Microstructure and mechanical properties of $\mathrm{Sn}-\mathrm{Bi}, \mathrm{Sn}-\mathrm{Ag}$ and $\mathrm{Sn}-\mathrm{Zn}$ lead-free solder alloys, J. Alloys Compd. 572 (2013) 97-106.

22. Zhai Q. J., Gao Y. L., Guan W. B., Xu K. D. - Role of size and cooling rate in quenched droplet of Sn-Bi eutectic alloy, Mater. Sci. Eng. A 441 (2006) 278-281. 


\title{
TÓM TẮT
}

\section{NGHIÊN CÚU CÁC QUÁ TRÌNH ĂN MÒN CỦA HợP KIM EUTECTIC Bi-42Sn HÀN}

\author{
Nguyễn Đăng Nam
}

Khoa Dầu khí, Truờng Đại học Dầu khí Việt Nam, Thành phố Bà Rịa, Việt Nam

Email: namnd@pvu.edu.vn

Bài báo nghiên cứu về sự thay đổi trở kháng trong trạng thái thụ động, tái thụ động và quá trình bắt đầu ăn mòn lỗ của hợp kim eutectic Sn-Bi. Phương pháp phân cực anốt được sử dụng để đánh giá trạng thái thụ động, ăn mòn lỗ và tái thụ động đồng thời kết quả này cũng được sử dụng để đảm bảo độ chính xác của phép đo điện trở kháng quang phổ. Phổ quang điện tử tia $\mathrm{X}$ cho thấy oxit thiếc tương tác với oxit bitmut tạo thành lớp màng thụ động của hợp kim. Bitmut phân hủy gây ra quá trình ăn mòn lỗ và oxít thiếc hình thành lớp màng tái thụ động.

Tù khóa: hợp kim Sn-Bi, ăn mòn, phản ứng điện hóa, điện trở kháng quang phổ. 